Article

\title{
Co-Producing a Vision and Approach for the Transition towards a Circular Economy: Perspectives from Government Partners
}

\author{
Anne P. M. Velenturf ${ }^{1, *}{ }^{\mathbb{D}}$, Phil Purnell ${ }^{1}$, Mike Tregent ${ }^{2}$, John Ferguson ${ }^{3}$ and Alan Holmes ${ }^{4}$ \\ 1 Resource Recovery from Waste Programme, School of Civil Engineering, University of Leeds, Leeds LS2 9JT, \\ UK; P.Purnell@leeds.ac.uk \\ 2 Environment Agency, Waste Strategy, Reading RG1 8DQ, UK; mike.tregent@environment-agency.gov.uk \\ 3 EcoideaM Ltd., 22 Atholl Street, Dunkeld PH8 0AR, UK; john.ferguson@ecoideam.co.uk \\ 4 Independent Scholar, Bristol BS1 5AH, UK; xalanholmes@talktalk.net \\ * Correspondence: A.Velenturf@leeds.ac.uk; Tel.: +44-1134-32279
}

Received: 2 February 2018; Accepted: 27 April 2018; Published: 2 May 2018

\begin{abstract}
The United Kingdom's (UK) economy is overly reliant on unsustainable production and consumption practices that deplete finite resources at rates that will increase production costs, business risk, and economic instability; it also produces emissions and waste that cause climate change and environmental degradation, impacting on well-being in the UK and beyond. The Resource Recovery from Waste programme (RRfW) promotes a transition towards waste and resource management in a circular economy that restores the environment, creates societal benefits, and promotes clean growth by engaging relevant actors in academia, government, and industry to co-produce a shared vision and approach that will realise such a transition. Sharing the RRfW's government engagement results, this article presents a positive outlook for changing the UK economy and society through waste and resource management practices that maximise the values of materials by circulating them in the economy for as long as possible. Key themes, regulatory instruments, a stable policy framework, and an approach for effective academic-government collaboration are proposed. Comparing the results to government plans in four UK nations shows great differences in progress towards realising a circular economy. The article concludes with recommendations to capitalise on opportunities for growth, innovation, and resilient infrastructure whilst contributing to quality jobs and welfare throughout the UK.
\end{abstract}

Keywords: resource efficiency; zero waste; Resource Recovery from Waste; low-carbon economy; circular economy infrastructure; clean growth; resource productivity; sustainable development goals; transdisciplinary research; participatory action research

\section{Introduction: Moving Away from the Resource Scarcity and Waste Overload Paradox}

Current patterns of production and consumption drive the emerging environmental crises of resource scarcity and waste overload [1-4]. Waste and resource management are directly related to the crossing of planetary boundaries that indicate the safe operating space of our society $[5,6]$. While growing resource use has increased the welfare of people, the resulting environmental degradation, climate change, and pollution violate human rights [7]. Hence, transforming management practices is crucial in order to solve global sustainability issues; radical changes in the ways that waste and resource flows are organised, i.e., the resource economy, are necessary [8].

Resource Recovery from Waste (RRfW) is an academic research programme envisioning a circular economy that contributes to a resilient and healthy environment and creates benefits for people such as reduced air pollution and high-quality jobs, and clean growth associated with greater resource 
productivity. The programme aims to facilitate far-reaching change in the waste and resource management landscape in the United Kingdom (UK). The programme establishes much-needed relations between a circular economy and sustainable development [9]. A circular economy can be conceptualised in many ways [9]; Resource Recovery from Waste adopted the definition provided by the UK's Waste and Resources Action Programme: “ . . an alternative to traditional linear economy (make, use, dispose) in which we keep resources in use as long as possible, extract the maximum value from them whilst in use, then recover and regenerate products and materials at the end of each service life" [WRAP 2016]. Governmental bodies in the UK tend to operationalise the circular economy concept with terms such as zero waste, resource efficiency, and, lately, resource productivity. Although the urgency of a transition towards a circular economy is well-recognised, progress has been slow and requires action, and hence strongly increased engagement, from all relevant actors [8]. RRfW collaborates with actors in academia, government, and industry to co-produce a more desirable future as well as an approach to realise such a shared vision. The objective of this article is to present the outcomes of the RRfW's initial government engagement. The results provide a unique insight into the perspectives of government actors, and these ideas are likely to shape future government strategies and plans.

\section{Methods: Co-Producing a Shared Vision and Approach for a Circular Economy}

\subsection{Overview of Resource Recovery from Waste Co-Creation Processes}

RRfW coordinates an academic, industrial, and governmental co-creation process to formulate a shared vision and approach aiming to bring waste and resource management within environmental and social boundaries; the reasoning for adopting this engagement strategy has been published separately [8]. The process consists of four steps (Figure 1):

(1) Formulate an initial vision within an academic RRfW team

(2) Develop the vision and approach to realise it with RRfW's governmental partners

(3) Extend findings with insights from RRfW industry partners

(4) Publish shared vision on waste and resource management

The first step has been completed [8]. This article is the result of the second step of the co-creation process, which is detailed further in this section.

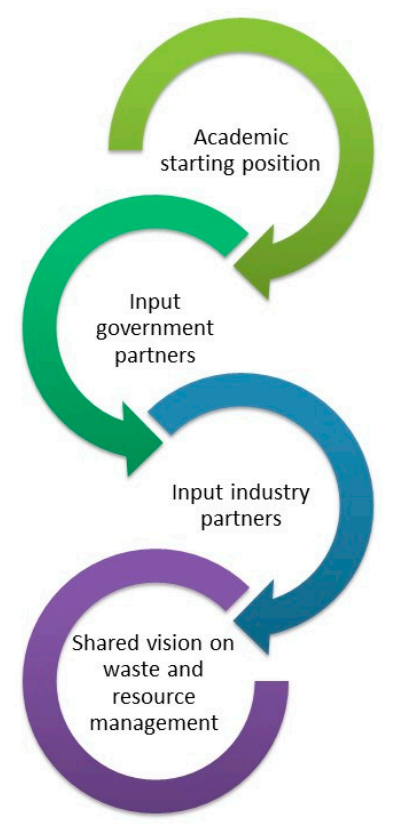

Figure 1. Resource Recovery from Waste (RRfW) co-creation process. 


\subsection{Engaging Governmental Partners}

Governmental partners were engaged in an iterative process of data collection and analysis (Figure 2), which was designed following the principles of participation process management and participatory action research [10-12]. Please find detailed insights of the application of these principles in RRfW in Velenturf and Purnell [8]. The RRfW process aimed at the co-production of a vision and approach with individuals who are active in waste and resource management policy-making and regulation in order to create ownership of the results and build commitment for uptake. In this article, the results are shared from the first stages of the government engagement in the participatory action research process, including: forming an initial stakeholder group, analysing the problem, identifying solutions, and appraising solutions to implement change (and striving to realise them through ongoing collaboration in the future). The process design was shaped by the RRfW academic team in collaboration with governmental partners, including the Department for Food and Rural Affairs (DEFRA) and the Environment Agency (EA); the latter was advised mainly on the positioning and wording of the questions listed below in order to bring forward the relevance of this research project for people in governmental organisations and increase the likelihood of a productive interaction during this study.

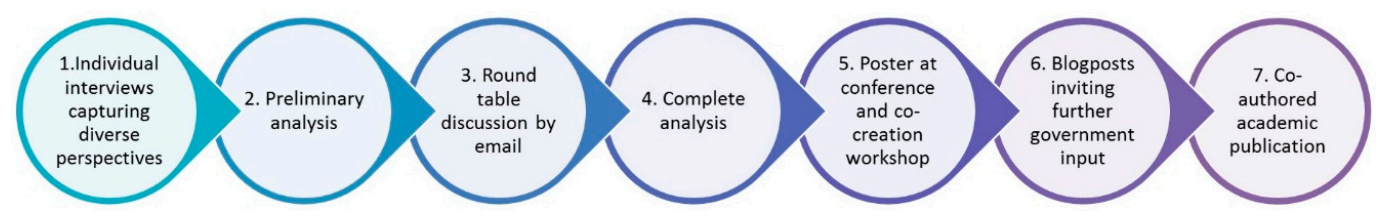

Figure 2. Government engagement process during data collection, analysis, and presentation.

Engagement activities were structured to capture broad perspectives, and then consolidated into the coherent vision and approach presented here in order to minimise any bias caused by anchoring around early or particularly strongly presented perspectives. Governmental partners of RRfW were invited to take part; further participants in related organisations were engaged through snowball sampling (see Bryman [13]).

First, participants were interviewed to capture the wide diversity of individual perspectives (Figure 2, step 1). Interviewees were asked to express their personal views; findings in this article thus do not represent formal organisational views, but rather are informed by participants' individual expertise in policy-making and regulation for resource recovery from waste. Interviewees included five participants from DEFRA, two from Zero Waste Scotland, and further interviewees from the Department for Business, Energy, and Industrial Strategy (BEIS), the EA, and the Scottish Environmental Protection Agency (SEPA). Semi-structured interviews covered four questions:

(1) For which organisation(s) are you working, and what is your role in waste and resource management?

(2) What would the resource and waste management landscape ideally look like by 2020, 2030, and 2050?

(3) If we would like waste management to be driven by environmental and social benefits in addition to economic benefits, what would be the key policy and regulatory approaches?

(4) How could RRfW best engage governmental organisations to translate knowledge into practice?

Notes from each interview were transcribed and shared with the participant to review and add any further points. In addition, RRfW participated in the BEIS "2050 Industrial Roadmaps and Circular Economy" workshop in October 2016, with presentations from senior staff of BEIS and DEFRA on industrial strategy and circular economy. The formally produced, but confidential, notes from the workshop were included in the analysis. A qualitative analysis, using open coding of the data $[13,14]$, extracted key themes for a vision for waste and resource management, policy and regulatory approaches, and engagement recommendations for academia (Figure 2, step 2). The contents 
of each key theme were described by summarising the similarities and differences in perspectives that were shared by the participants.

The preliminary analysis was organised into a table including (a) preliminary results; (b) questions to clarify similarities and differences in perspectives; and (c) space for comments by participants. The table was shared in a 'virtual roundtable', engaging interviewees in an email discussion of the preliminary results to answer questions and invite comments (Figure 2, step 3). The additional information was included in the final stages of the data analysis (Figure 2, step 4), which resulted in two outputs. First, a poster was presented at the annual RRfW conference and engagement workshop for industrial partners (Figure 2, step 5). Second, results were presented in a blog-post series via the RRfW social media channels in January 2017 (Figure 2, step 6), with a membership of (at that time) over 300 followers, including key senior individuals who were active in governmental organisations working on waste and resource management [15-17]. Further contributions to the shared vision and approach were invited and included in the finalised analysis presented here; this led mainly to discussion and reflection upon formal government strategies and plans for waste management and the development of a circular economy across the countries of the UK. Finally, this publication is co-authored by RRfW (former) governmental partners (Figure 2, step 7). In summary, participants who were active in policy-making and regulating waste and resource management were involved in the engagement process, from its early design in 2016 throughout data collection, analysis, and presentation of the first results in 2017 and publication in 2018.

\section{Results}

The engagement process identified key themes (Section 3.1) as well as policy and regulatory approaches to realise increasingly sustainable waste and resource management (Section 3.2); and processes through which academia and governmental organisations could collaborate effectively in the transition process (Section 3.3).

\subsection{Key Themes for Vision on Waste and Resource Management}

Participants from across the government generally envisioned a long-term future for waste and resource management that moves away from end-of-pipe approaches and towards maximising the value created from materials whilst keeping them in the economy for as long as possible. End-of-pipe approaches address waste management issues only by recovering valuable resources, rather than integrating a focus on waste prevention and improved whole system design for resource management; for example, by offering a technology to deal with plastic packaging waste without other system interventions to design recoverable or reusable packaging solutions. The value of materials can be maximised by adopting more proactive strategies that consider how resources are transformed during each stage of the product life cycle, including end-of-life options for reuse, dismantling, and/or recycling. All of the participants agreed that waste elimination was the preferred prospect, but opinions differed around its feasibility, how the vision should be realised, and the associated wider contextual changes that this might entail. These differences will be discussed in the key themes below.

\subsubsection{Integrating Economic with Social and Environmental Values}

The first theme focussed on the ways in which economic benefits can be integrated with-and bring about—social and environmental values. While there appeared to be a general agreement that the current growth model needs to change, perceptions differed regarding the compatibility of economic growth with the realisation of a circular economy. Perceptions around what constitutes growth varied, and arguably were not focussed solely on economic progress, but also included social and environmental improvements. Even when an economy does not grow in financial terms, it can still grow in terms of environmental and social progress. For example, indicators for well-being, equality, and cultural diversity are just as relevant. However, valuing these on equal terms with economic growth requires a fundamental shift in economic theory and practice, particularly in government. 
Integrating environmental and social values into valuation methods for economic progress requires the development of new metrics. Views differed on the ways in which metrics that represent environmental and social values could be integrated with economic value. Environmental and social externalities can be internalised into economic costs and benefits. This implies monetising currently externalised impacts, such as carbon pricing, landfill and extraction taxes, etc. but such an approach can be prone to manipulation (see for example the Interpol Environmental Crime Programme [18]). As a more transparent alternative, environmental, social, and economic values could be assessed in an integrated manner without being collapsed onto financial value alone [19], but only a few modelling approaches are available. Despite recognising the limitations of focusing on money only (See for example [20]), many government departments still appear to keep a sole focus on economic metrics. One way forward would be including social and environmental metrics in models used by the Treasury.

Decoupling consumption rates from economic growth, as well as resource use from waste production, could be supported by such altered metrics to help internalise currently externalised benefits and impacts. Decoupling is partly about dematerialisation, i.e., making better material choices and using less materials in products, and partly about extending life cycles through improved design, reuse, repair, and remanufacturing. In current economic models, this would appear as a reduced consumption rate; such systemic failures demonstrate that metrics need to be adapted to support maximising the economic, social, and environmental values created and destructed throughout the life cycles of products, materials, and components.

\subsubsection{Supporting Secondary Resource Markets}

The second theme revolved around the ways in which secondary resource markets could be supported. Participants agreed that markets for wastes and byproducts need to emerge in order to close resource loops in our economy. In addition to the transformation discussed in Section 3.1.1, a range of additional potential market and cultural changes were proposed.

Transaction costs for secondary resources tend to be higher than the use of primary materials (evidenced by for example OECD and WRAP [21,22]). This is particularly the case for construction and demolition waste (e.g., glass, timber). Such barriers need to be removed. For example, some participants suggested that the use of secondary resources could be supported by a ban/restriction on primary materials—which are currently mainly in place to reduce pollution-when secondary resources are available, and incentivise the use of recyclates further with levies, such as strived for through the Aggregates Levy (Further details at: https:/ / www.gov.uk/topic/business-tax/aggregates-levy), combined with green procurement government policies. Information and control on recyclate quality must be improved to support the uptake of secondary materials. Upstream in the supply chain, a level playing field could be created by integrating the real environmental and social costs into the extraction or production of primary resources.

Cultural changes were closely associated with market evolution. While some participants believed far-reaching changes would occur before 2050, others did not foresee radical shifts in behaviour patterns at all; this uncertainty will have major implications for installing the physical and economic infrastructure required for the processing of secondary resources. Moving from the current supplier-led markets to demand-led markets would arguably reduce waste arisings. Rather than producers driving up demand, consumers could indicate what they really need e.g., through 'on-demand' business models (such as those described in Bocken et al. [23]). Digitisation could help build the required connections between suppliers and consumers, but also poses challenges through increased opportunities for businesses to generate demand using targeted marketing (further discussed in the next paragraph). Behavioural change requires a clear, strong regulatory framework in support of positive behaviours. However, not everyone was convinced that far-reaching changes in consumption patterns are feasible (although governmental bodies have been proven wrong before in industry appetite for change, for example in the case of electric vehicles uptake). If one accepts that consumerism will keep centre stage in our society, then infrastructure and markets need to have sufficient capacity to provide demanded products and 
recycle them as well. In such scenarios, companies rely more heavily on innovative business models to close resource loops post-consumption, such as products as services, product life extension through e.g., reuse, and collaborative consumption, i.e., product sharing (for further details on circular business models please see Bocken et al. and Accenture [23,24]). Moreover, there would be more demand for improved recycling technology to process all waste arisings.

\subsubsection{Enabling Innovations}

The third theme referred to enabling innovations: digitisation, material and product design, and business model innovation. Digitisation offers opportunities in terms of enabling recycling, especially in combination with the internet, for example through data collection and sharing on waste flows, raw materials information systems, and sharing scientific results via online databases. Conversely, digitisation is associated with increasingly complex e-wastes. Material and product design can enable recycling by designing end-of-life options for products including electronics, packaging, etc. Such improved design of materials, components, and products requires both regulatory support to prevent designed obsolescence, and instead, build-in reparability and recyclability, for example disincentivising rapid turnover products that generate large quantities of waste that are difficult to recycle. Co-polymer designs of bottles with different plastic tops and bodies were widely cited as an example (for an overview of resource recovery from plastics, see Hahladakis et al. [25]). The general consensus was that improved recycling technologies and product designs would need to be combined with innovative business models to enable the circular economy (as discussed above).

\subsubsection{Whole System Approach Identifying Key Intervention Points}

The fourth theme focussed on the need for whole system approaches that identify key intervention points. One way to identify such points is a sectoral approach, focussing attention on priority sectors such as food waste, plastics, construction and demolition, etc. Sectors or materials could be prioritised by value and environmental impact. Further intervention points could be defined by assessing risks along whole (circular) value chains to identify hotspots.

Alternatively, three cross-sectoral areas for intervention were suggested, focussing on:

(1) Higher end of the waste hierarchy (Figure 3): All participants were coherent in suggesting a move away from end-of-pipe approaches towards an accelerated focus on the top of the waste hierarchy i.e., more waste reduction, reuse, and recycling. However, the ways in which this needs to be realised varied between regulating/charging and incentivising (further discussed in next section).

(2) Carbon benefits of improved waste and resource management: Carbon emissions were associated with waste and resource management. With regard to the embodied carbon in materials, components, and products, i.e., the energy used to extract/grow and process the resources into its current functional form, recycling/reuse may deliver carbon savings when compared to processing virgin materials. In energy-intensive industries, waste and resource management are increasingly important for decarbonisation now that savings through energy-efficiency measures are reaching thermodynamic limits. Waste infrastructure such as biogas and energy-from-waste also play a direct role in the decarbonisation of the energy sector. Finally, the ways in which carbon emissions have climbed government and industry agendas could serve as an example for waste management.

(3) Waste/circular economy infrastructure: Enabling the circular economy requires a better understanding of existing waste infrastructure, including location and capacity (such as also analysed in Purnell [26]). Arguably, a decentralised waste infrastructure would benefit the circular economy, allowing the segregation of waste streams to realise resources and value as close to the point of discard as possible, whilst offering the best opportunity to stimulate regional economies. However, the feasibility of regional waste treatment will depend on the materials concerned 
(also see Jensen [27]); increasingly complex materials are expected to pose new technological challenges for the waste industry. Nevertheless, exporting wastes as Refuse Derived Fuel/ Solid Recovered Fuel was generally perceived as a missed opportunity to generate value from material recovery for the UK economy. Re-imagined waste infrastructure and procurement systems in the UK could improve these outcomes.

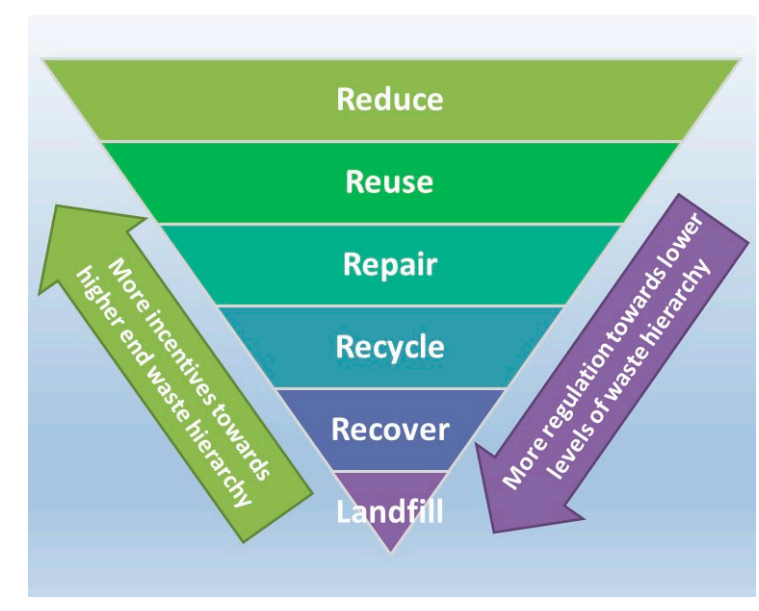

Figure 3. The transition towards a circular economy can be motivated through a combination of regulation and incentives.

\subsection{Policy and Regulatory Approaches}

\subsubsection{Key Policy Directions}

To realise the vision and work on the key themes outlined above, interviewees discussed various policy and regulatory approaches. Five focal areas for policy development were indicated:

(1) Longer term policies that are stable and predictable. Such policies would enable investment and business model innovation.

(2) The vision focussing on the higher levels of the waste hierarchy was reflected in the suggestion to focus policies on resources and resource efficiency rather than waste and waste reduction.

(3) Build on the European Union (EU) Circular Economy Strategy to maintain integrity with EU resource, waste, and circular economy policies.

(4) Prioritise the reduction of single use and superfluous products/packaging as well as the use of hazardous materials in products when it poses barriers to recycling.

(5) Develop circular economy infrastructure in support of a decarbonisation agenda.

Overall, policies should strive to make the concept of waste redundant Whilst recognising that there may always be wastes that are currently considered "unavoidable", it should still remain the ultimate objective of all policy efforts.

\subsubsection{Regulation and Incentives}

Turning to regulatory approaches, a combination of incentives and regulations were suggested to focus efforts on the higher levels of the waste hierarchy. The overriding idea is that each level of the waste hierarchy needs its own mix of incentives and regulations, with more 'carrot' or 'save as you recycle' approaches towards the higher levels, and more use of regulatory 'sticks' or taxation to prevent resources from moving down the hierarchy (Figure 3). However, across government, there were pertinent differences as to whether incentives should be preferred over regulation, although evidence suggests that regulating i.e., legal obligations motivate more change than incentives [28]. 
Further diversification of regulatory approaches may be required for different sectors, as sectors are subject to varying sets of technological and market constraints and opportunities.

Six groups of regulatory instruments were discussed:

(1) Taxation and tax breaks - To promote reuse and repair in addition to recycling. Taxation could motivate technological change, potentially further mechanisation, and support a transition from labour-focussed to resource-focussed processes. Taxation could also play a role in internalising elements of resource value that are currently largely externalised, such as the end-of-life impacts. Such tax approaches would enable prioritising resource use by the value of the products, components, and materials being produced; however, it requires new frameworks and tools to measure, categorise, and prioritise resource use by application.

(2) Reporting - It is necessary to identify and understand resource flows, especially at higher levels of the waste hierarchy such as reuse (further details in this comprehensive study of reuse in the UK and Ireland [29]). Reporting could be incentivised by tax breaks in reuse and repair. Nevertheless, motivating reuse and repair should not create perverse incentives that make waste prevention and reducing resource use relatively less attractive. In this respect, extended producer and consumer responsibility can play an important role.

(3) Extended producer and consumer responsibility-Extended producer responsibility (EPR) can help target specific waste/ resource streams, support schemes to make polluters pay, and motivate designing wastes out of the system. EPR should be combined with an increasing emphasis on consumer responsibility in order to improve the quality and quantity of wastes feeding into the waste management industry, such as for example through deposit refund schemes on items that are difficult to recycle (low-energy light bulbs, batteries, etc.). The value of EPR would be greatly enhanced by better understanding the roles and responsibilities of consumers.

(4) Product bans or product standards-Connected to EPR, product bans could offer a strong instrument to intervene. However, such bans were contentious and, alternatively, products standards and the inclusion of externalities in economic value were proposed.

(5) Mandatory recycling regimes-In support of extended producer and consumer responsibility, markets could be further directed by mandating recycling regimes. Such mandates are expected to improve the quality of recycled resources, which is an essential requirement to realise the circular economy.

(6) Waste Prevention Act-Waste and resource management can play an important role in carbon reductions, as supported by the Climate Change Act. Waste prevention was perceived of such importance that it should not be voluntary and, instead, should be embedded in a Waste Prevention Act.

\subsubsection{Reviewing the Policy and Regulatory Framework}

When introducing the newly proposed regulatory approaches above, participants considered that reconsideration of the existing policy and regulatory framework would also be necessary. First, regulatory barriers to closing resource loops need to be addressed-for example, the end-of-waste pathway needs to be more transparent and easier to achieve (end-of-waste procedures are detailed on the UK government website [30]). The regulatory system should become less centred on waste and focus more on valuing resources and prioritising risks within the whole cycle of production and consumption. Second, it is necessary to realign support for competing incentivised supply chains. Linked to realigning incentives, regulatory efforts should focus on those who can actually (pay for) change in waste and resource management. For example, local councils carry responsibility for recycling, but austerity measures cause difficulty in achieving obligations (such as those evidenced by NAO and Velenturf [31,32]). Similarly, various energy intensive industries are reaching their boundaries for resource and energy efficiency; hence, sectoral differentiation in policy and regulation may be required to only target sectors where significant improvements are feasible. 


\subsubsection{Education for Circular Economy Transition}

Building on the argument that regulatory approaches should focus on those who can change practices, education and support play an important role. Local councils play a key role in realising waste infrastructure and cultural change. The Local Government Association (LGA) is well positioned to provide information to local councils about circular economy and best practice. Such knowledge is also crucial for government in general, but it is especially important for those in power to lead on waste and resource management. Other than government actors, it is also important to educate households and businesses. Business needs to be educated as to what the circular economy is and what opportunities exist, such as for example in terms of reducing costs, increasing profits, and/or long-term business viability, and reducing risks around material supplies (these economic motivations are broadly in line with Velenturf [33] and need to be further developed in the next step of the RRfW co-creation process with industry that is outlined in Section 2). Education, as tied into the sectoral differentiations introduced above, should: focus on general concepts such as business planning, support the adoption of circular economy approaches, champion successful cases, and disseminate good practices between local authorities and businesses. Academia is well placed to provide consistent, credible, and impartial materials for all areas of education and behaviour change.

\subsection{Effective Collaboration between Academia and Government}

In what ways could academics best collaborate with governmental partners in order to develop the policies and regulations discussed above? This section presents recommendations from governmental partners for academics on potential engagement methods, organisations, government processes, and the positioning and generation of research outcomes.

Participants felt that academics should engage governmental organisations from the start of research projects. This early engagement should be followed up by regular contact throughout the project. Such regular contact also helps government organisations to stay up-to-date with relevant policy processes (further discussed below), offering opportunities for participation and uptake. The participation of government partners at multiple levels was seen as crucial in the transition process towards more sustainable waste and resource management. Far-reaching changes are needed at all levels of government, and throughout society; hence, to bring about such systemic change, "taking everyone with us" is important. Only with such broad engagement approach can academics capture and integrate all of the relevant perspectives, educate key actors, and present a shared pathway towards a sustainable circular economy.

Government partners at all levels need to be engaged, from politicians to departmental policy and technical teams, and parliamentary groups and committees. The involvement of politicians such as Members of Parliament throughout the UK (Details of British parliament system at https: / /www.parliament.uk/about/mps-and-lords/members/) is important in order to build up credibility in the political arena. Important departments to engage about waste and resource management are DEFRA, BEIS, and the Treasury in England, and equivalent departments in the devolved administrations, which are in crucial positions for waste and resource management policy and regulation, industrial strategy, and waste infrastructure. MHCLG and the equivalent departments in the devolved administrations are also of key importance, as they regulate the budgets available for the local councils that are responsible for municipal solid waste. Engagement should include both technical officers as well as policy makers. The membership of various parliamentary groups and committees is another way of channelling engagement and impact. The All-Party Parliamentary Sustainable Resource Group is a good conduit for influencing in England, as is the Environmental Audit Committee. Additionally, the timely engagement of regulators and regional governments is crucial for the implementation of sustainable waste and resource management strategies and measures.

It is important to engage the governmental actors mentioned above, because they are closely involved themselves or indeed coordinate various relevant activities to which academics could contribute. For example, in departments such as DEFRA, BEIS, and the Treasury, engagement could 
take the form of direct and regular meetings to exchange knowledge or through contributions to consultations such as for the industrial strategy, bioeconomy strategy, and approaches to support the circular economy. Contributions to standards, for example BREFs (B: Best available techniques, REF: REFerence documents) and the recycling protocol for demolition and construction waste, are another option. To make results more accessible for government partners, academics could also contribute to POST (Parliamentary Office of Science and Technology) notes and the Raw Materials Information System. Furthermore, organising research results and data in existing, or newly launched, online databases would make research results on waste and resource management more accessible. Finally, organising events in Westminster and the devolved parliaments/assemblies offer another platform to engage politicians and other government actors.

Two interlinked approaches to position research outcomes were brought forward. The first pertains to whole system approaches. The ability of maintaining the bigger picture of whole systems is a core strength of academia. However, the government changes holistic systems through key intervention points. Moreover, they only have limited resources to intervene, and hence need to maximise the effects with minimum resources. Therefore, it is recommended that academics provide specific measures targeted at sectors and materials, within the context of the whole system. In other words, academics should present whole system models, but with more practical recommendations.

Another key approach in presenting research outcomes revolves around integration. Building on the observation above that actors throughout society need to change, at all levels of government as well as across industry and in the general public; academic work should integrate the diverse stakeholder perspectives. Priority should be given to the integration of strategies for the circular economy with the wider agenda for economic development and protection of the environment. Practical advice to support such an integrated, cross-government, approach is in demand. Recommendations in the form of new metrics to integrate into economic development models would be valuable, for example, circular economy metrics or sets of metrics that include environmental and social indicators of progress in addition to economic metrics. Data associated with such new as well as existing metrics to understand whole systems, in addition to data covering gaps in models used by the government, would also help governmental partners better understand whole systems. Academia should support a more integrated understanding of promoting sustainable waste and resource management by joining up the elements of the circular economy. While government interventions tend to focus on sectors and materials, and academics should translate recommendations into such terms, academia should also clarify how materials, components, and products can circulate through the economy through interconnected sectors. In other words, academics should identify where joined-up interventions for two or more sectors are necessary in order to support the emerging circular economy. Finally, it is strategically important to integrate perspectives within academia. Too widely differing academic perspectives are open to misuse by transition sceptics looking for reasons not to use the provided evidence and change any practices.

Turning towards the research activities supporting effective collaboration with government partners, three activities are suggested, but many more are possible:

(1) Identify policies and regulations linked to the research project.

(2) Carry out a situational analysis to understand if, and in what way, a new approach or technology could be realised within the policy and regulatory context.

(3) Connect solutions and recommendations explicitly to policies and regulations in a specific region.

\section{Discussion: Reflections on RRfW Vision and Existing Government Strategies}

\subsection{Comparing the Academic and Governmental Narratives}

Comparison of the "governmental" narrative outlined above to the opening narrative of the Resource Recovery from Waste programme [8] shows that both perspectives largely align. Importantly, government and academic perspectives agree on the necessity to transition towards a circular economy, 
moving away from end-of-pipe solutions and increasingly focussing on upstream supply chain changes to bring materials, components, and products to market that can easily be reused, dismantled, and recycled. This is especially the case for new complex materials and e-wastes. The need for new economic theory and practice was recognised, including the ability to assess the true costs of processes in terms of economic, social, and environmental values throughout whole supply chains; note that technical value was not discussed by government partners. The circular economy, and the associated increased need for innovation, was perceived as an opportunity for the British economy. However, reaping the benefits will depend on understanding and realising the required waste and resource management infrastructure in support of a circular economy (also see [26]).

The government and academic narrative agreed on the necessity for more action supporting sustainable waste and resource management from actors throughout society. Everyone needs to be involved in the transition process. Academia is particularly well-placed to keep an overview of the bigger picture, suggesting alternative economic development pathways and identifying key intervention points. The need for continuous engagement of non-academic stakeholders in academic research and formulating practical recommendations were a shared concern.

Differences between the academic and governmental narrative were relatively diffuse. Discussions with partners in governmental organisations did not reach as widely as the academic narrative; for example, the dependency of the economy on society and the environment was less pronounced. However, such dependencies were not directly questioned either by governmental contacts engaged for the narrative presented herein. Similarly, linkages between waste management, the overexploitation of resources, and quality of life in the UK were less clear. Governmental and academic narratives diverged on questions regarding whether changing consumer behaviour is a necessity before marketing products that are more amenable to recycling, and whether internalising environmental and social values into financial cost-benefit analyses will really support a transition towards a circular economy. Finally, while clear agreement emerged on the issue of data deficiencies, the governmental response was centred on increasing efforts for data acquisition and digitisation opportunities, while academia may focus more on developing tools to deal with imperfect data and/or data that is difficult to combine. These two approaches could be complementary if correctly designed.

\subsection{Reflecting Upon Government Strategies in England, Scotland, Wales, and Northern Ireland}

This article has presented the personal views of those working in governmental organisations, and this section complements those perspectives with the formal government positions. As waste is a devolved matter in the UK, the key themes identified in this article are compared to the aspirations presented in the visions, strategies, and plans for the promotion of a $\mathrm{CE}$, resource recovery, and waste management (as far as they are available) in England, Wales, Northern Ireland, and Scotland.

\subsubsection{Wales}

In Wales, the circular economy is promoted through the national waste strategy "Towards Zero Waste" [34] under the leadership of the Cabinet Secretary for Environment and Rural Affairs. The strategy was introduced in 2010, and is due for an update in 2018, for which consultation is currently ongoing. It integrates waste management with other policy areas, including the Well-being of Future Generations (Wales) Act 2015 and Environment (Wales) Act 2016, striving to achieve the goals of the One Wales: One Planet sustainable development scheme [35]. The national waste strategy is implemented through a series of sector plans and a programme of government initiatives, including e.g., the statutory recycling targets and investment in WRAP Cymru [36] and, more recently, a Circular Economy Investment Fund for small and medium sized companies [37].

Recently, the Welsh government published the Natural Resource Policy [38]. This policy recognises natural resources as the backbone of the economy and society, adopting an ecosystem stewardship approach (such as that discussed in the Resource Recovery from Waste vision in Velenturf and Purnell [8]). Clearly, this policy takes a next step in Wales' transition towards an economy that is 
sustainable by design, putting the environment and human well-being upfront, whilst promoting sustainable growth through renewable energy, resource efficiency, and the circular economy as expressed in this quote: "The evidence shows that the inefficient use of natural resources is affecting the availability of primary resources and materials now and in the future. In addition, the use of these resources places significant pressures on our natural resources and ecosystems in the form of damaging pollution and climate change. To reduce these pressures, we need to increase waste prevention and promote reuse, recycling, and recovery" [38] (p. 11).

Similar to the zero waste strategy, the natural resource policy is integrated with the Well-being of Future Generations [39] and Environment Act [40], while strongly linking to the international agreements UNFCCC (climate change), CBD (biodiversity), and UN SDGs (sustainable development). Finally, the national strategy "Prosperity for All" links into this framework of strategies, policies, and agreements, too [41]. However, realising these plans will require considerable regulatory reform, and this appears to be still in its early stages.

When comparing the Towards Zero Waste strategy and the Natural Resources Policy to the themes identified in this research, it is clear that the Welsh government have not only already integrated all of the aspects (Table 1), they have also added further themes, such as:

- Ecosystem stewardship and biodiversity

- Integrated governance

- Investment support for $\mathrm{CE}$ and resource efficient public procurement

Table 1. Comparative analysis of key themes distilled from government specialists' personal views and formal government visions, strategies, and plans for circular economy, resource recovery, and/or waste management for as far as these documents were published by the devolved administrations within the United Kingdom (UK) (green=included; orange=partly included; and red=not included in formal government documents).

\begin{tabular}{|c|c|c|c|c|}
\hline \multirow[b]{2}{*}{ Themes } & \multicolumn{4}{|c|}{ Country } \\
\hline & Wales & $\begin{array}{l}\text { Northern } \\
\text { Ireland }\end{array}$ & Scotland & England \\
\hline \multicolumn{5}{|l|}{$\begin{array}{l}\text { INTEGRATING ECONOMIC WITH SOCIAL AND ENVIRONMENTAL } \\
\text { VALUES }\end{array}$} \\
\hline Radical change in economic theory and practice & Yes & Partly & Partly & No \\
\hline Progress redefined to include social and environmental factors & Yes & Yes & Partly & Partly \\
\hline Maximise environmental, social and economic value created from resources & Yes & No & Partly & No \\
\hline Internalise or integrate environmental, social and economic metrics & Partly & No & Partly & No \\
\hline \multicolumn{5}{|l|}{ SUPPORTING SECONDARY RESOURCE MARKETS } \\
\hline $\begin{array}{r}\text { Decoupling: consumption from economic growth; environmental, social and } \\
\text { economic metrics }\end{array}$ & Yes & Yes & Yes & No \\
\hline Keep materials in economy as long as possible & Yes & Partly & Yes & Partly \\
\hline Incentivise/ regulate emerging secondary resource markets & Yes & Yes & Yes & Yes \\
\hline From supplier-led to demand-led markets & Yes & Partly & No & No \\
\hline \multicolumn{5}{|l|}{ ENABLING INNOVATIONS } \\
\hline $\begin{array}{r}\text { Business model innovation vs. business as usual with improved recycling } \\
\text { technology }\end{array}$ & Yes & Partly & Yes & Partly \\
\hline Material and product design including end-of-life options & Yes & Yes & Yes & Yes \\
\hline Digitisation enabling recycling, but growing e-waste & Partly & No & Yes & Partly \\
\hline \multicolumn{5}{|l|}{ WHOLE SYSTEM APPROACH IDENTIFYING KEY INTERVENTION POINTS } \\
\hline Move away from end-of-pipe approaches and higher up the waste hierarchy & Yes & Partly & Yes & Partly \\
\hline Decarbonisation + has to include waste and resource management & Yes & Partly & Yes & Partly \\
\hline Enable CE through (decentralised) waste infrastructure & Yes & No & Yes & No \\
\hline Whole system approach but identify key intervention points for targeted action & Yes & Yes & Yes & Partly \\
\hline $\begin{array}{l}\text { REALISE RADICAL CHANGE THROUGH ENGAGEMENT OF } \\
\text { GOVERNMENT, INDUSTRY, ACADEMIA AND GENERAL PUBLIC }\end{array}$ & Yes & Partly & Partly & Partly \\
\hline
\end{tabular}




\subsubsection{Scotland}

Scotland has a longer history of working towards a circular economy, stemming from the Zero Waste Plan [42]. The focus on waste minimisation has grown to include resource efficiency and circular economy, which is connected to the decarbonisation of the economy. The EU circular economy Package [43] is seen as leading the uptake of circular practices, providing a strong basis for the detailed strategy "Making Things Last" for the Scottish circular economy [44]. The circular economy strategy integrates objectives of the Zero Waste Plan [42] and waste prevention strategy "Safeguarding Scotland's Resources" [45], and is linked to "A Manufacturing Future for Scotland" strategy [46], in which circular economy takes centre stage in the first key action to "Deliver concrete initiatives to boost productivity including leadership, employee engagement and skills, energy efficiency, and the adoption of circular economy approaches across the manufacturing sector". In Scotland, circular economy is explicitly linked to zero waste and resource efficiency; resource efficiency in its turn has been integrated with decarbonisation and the preservation of natural capital as part of investment priorities set out in the economic strategy [47].

The Scottish circular economy strategy strongly embraces the waste hierarchy, with plans and priorities to promote circularity via every level of the hierarchy. It envisions the decoupling of economic growth from resource use, through increased resource productivity [48], as formulated in this quote: "All of the priorities in chapters covering loops of the circular economy (design, reuse, repair, and remanufacture) will also contribute to waste prevention, helping to decouple resource use from economic growth" [44] (p. 11).

Despite the clear plans for decoupling, compared to the themes identified in this research, the overall strategy seems less radical and integrative in terms of social changes and reforming perceptions of economic progress and associated values (Table 1). While environmental and economic objectives are well-integrated, the social interests appear to be more in the background. This is, for example, reflected in the way that progress is defined with social factors such as skills, jobs, and social enterprises, but less about the bigger picture of welfare and viable communities. Meanwhile, the proposed metrics framework, which appears to be in its early stages of development, entirely focusses on 'classic' indicators such as reducing carbon emissions and wastes. Moreover, the strategy aims for lower costs and economic growth for Scotland. Environmental limits, and particularly resource scarcity, appear to be the key drivers for Scotland, as framed in "Safeguarding Scotland's Resources" [45] (p. 6): "The overall aim of this programme is to prevent waste, increase resource efficiency, and enable a shift towards a more circular economy". This confirms the predominantly environmental and economic basis for the Scottish circular economy from a materials' management perspective. Overall, focus does not seem to be as much on the reduction of consumption and promotion of 'sufficiency' such as in Wales, indicating perhaps a less radical view on societal change. That said, the resource management blueprint does include ideas for a culture change regarding resource efficiency [45]. While the envisioned changes for Scotland may be less radical in nature, the strategies and plans are coherent and are operationalised with detailed actions.

\subsubsection{Northern Ireland}

Northern Ireland does not have a circular economy strategy yet [49]. Circular economy does get mentioned in the waste management strategy for Northern Ireland, "Delivering Resource Efficiency" [50], linking waste management and resource efficiency to the low-carbon and circular economy. The strategy defines resource efficiency as "using resources in the most efficient way while minimising the impact of their use on the environment" (p. 6). While it recognises that waste should be treated as a resource with a value, it remains viewed mostly as a risk to the environment and people rather than recognising it as an opportunity to transform the economy. Recycling targets are integrated to deliver objectives on protecting people and the environment, and creating safer communities. Nevertheless, waste management is recognised as part of the green economy, and relations are established with sustainable development, too. 
The Northern Irish sustainable development strategy "Everyone's involved" [51] presents ambitious plans around four key themes: economic prosperity, social cohesion, environmental protection, and meeting national and international responsibilities. The strategy strongly centres on climate change, reducing carbon emission, and energy generation. While the strategic objectives do mention resource efficiency, the translation into actions is limited to increasing the resource efficiency of businesses and reducing landfill. No specific investments into waste, resource recovery, or the circular economy infrastructure are included. Looking into the details of investments into infrastructure, the Strategic Waste Infrastructure Programme launched in 2008 was designed to deliver landfill reduction targets (https:/ / www.daera-ni.gov.uk/articles/waste-infrastructure-and-secretariat-office\#toc-0). Initially, the programme was designed to be delivered through three projects, striving to deliver waste infrastructure including mechanical, biological, and energy-from-waste treatment facilities (http:/ / www.agendani. $\mathrm{com}$ /waste-infrastructure/). However, delivery was protracted, and eventually two of the three projects were abandoned due to procurement challenges and the success of the waste prevention measures, driving down demand for this type of facility.

Waste prevention was supported by the EU Waste Framework Directive, obliging all member states to prepare a waste prevention plan. In Northern Ireland, the introduction of the new waste management strategy (discussed above) and the Waste Prevention Programme increased efforts to "drive waste up the waste hierarchy; to deliver resource efficiency" [52] (p. 6). The waste prevention strategy strives to continuously reduce waste arisings in Northern Ireland, delivering objectives on decoupling, encouraging people to increase resource efficiency and produce less waste, and integrating resource efficiency and waste prevention into business management and project planning.

Comparing the Northern Irish context to the key themes in Table 1, it is recognised that progress should be redefined to include environmental and social—in addition to economic-factors. However, for waste and resource management, this has not translated yet into values and metrics to progress in such an integrated manner, transforming the economy to become more circular. Old perspectives on waste management appear to prevail in government, with a bias towards environmental and health risks and Energy-from-Waste, and little action beyond achieving landfill reduction targets. It can be concluded that a good start has been made in preparing the government strategic context for waste and resource management integrated into sustainable development and set for radical economic and societal change; however, this has not crystallised yet into substantial, concrete progress in line with this framework.

\subsubsection{England}

Similar to Northern Ireland, England does not have a circular economy strategy. The waste review 2011, which was initiated by the previous coalition government, set out a comprehensive view to move towards a green, zero waste economy delivering economic and environmental benefits [53]. However, the waste management plan [54] and associated post-adoption statement [55] indicate a step backwards from the radical economic and societal reforms required for sustainable waste and resource management. The plans voice the ambition to achieve zero waste as part of the transition towards a sustainable economy; however, they also accept waste as unavoidable. Framed according to the waste hierarchy, it delivers the minimum requirement for the revised Waste Framework Directive aim as "to protect the environment and human health by preventing or reducing the adverse impacts of the generation and management of waste and by reducing [the] overall impacts of resource use and improving the efficiency of such use" (p. 34).

The waste management plan is complemented by the waste prevention programme for England [56] and a quality action plan [57]; both make positive statements about the environmental and economic values that can be created by driving waste management higher up the waste hierarchy. However, the overall picture of waste strategies and plans appears to be somewhat ambivalent, with contradictory statements such as those indicated above around zero waste yet readily accepting unavoidability, a willingness to support secondary resource markets in the UK yet justifying large-scale 
exports, incorporating the waste hierarchy-including the requirement for a diverse waste and reprocessing infrastructure-yet directing public investment nearly solely to energy recovery (also see Purnell [26]), and setting out collective responsibilities yet delegating responsibility to deliver to local authorities and the EA with diminishing budgets. Hence, in comparison with the key themes in Table 1, England appears the least green in terms of waste and resource management.

Perhaps the picture in England is constrained by the political complexity and available capacity in ministries that are, unlike their devolved counterparts, not only responsible for England but the whole UK. For the UK as a whole, there is no circular economy strategy. However, the circular economy has been incorporated into the new industrial strategy "Building a Britain fit for the future" [58]. The importance of a circular economy, resource efficiency, and resource productivity are recognised in achieving clean growth i.e., increased economic growth while decreasing carbon emissions [59]. These strategies are supported by the 25-year Environmental Plan [60] and forthcoming Resource and Waste Strategy, aiming to make the UK a world leader in competitiveness, resource productivity, and resource efficiency.

Government action now needs to follow this positive curve. While the benefits and feasibility of measures increasing resource efficiency are long known (e.g., WRAP [61]), in practice, government action has focussed on energy efficiency rather than material efficiency, which is perceived as more of a future challenge [59]. Similarly, the National Infrastructure Delivery Plan 2016-2021 [62] shows a relatively limited investment in waste management, justified by the sufficient capacity to meet EU landfill diversion targets. Investments are scheduled are for ca. $80 \%$ in Energy from Waste. The government should invest in diversifying waste infrastructure to include material reuse, recycling, and recovery that is in line with its ambition to have the infrastructure in place and move towards a high-value circular economy in the UK [26].

\subsubsection{Comparison of Waste Management, Resource Recovery, and Circular Economy}

Comparing the analysis from the four nations in Table 1 confirms that changing practices present the most challenges. While governments generally recognise that progress includes environmental and economic factors, social benefits and impacts tend to be underrepresented across the UK. Moreover, the translation of these new visions around progress into actual values and metrics lags behind, and this is where governments can strengthen their strategies and plans. Personal and formal government perspectives were relatively aligned regarding the promotion of secondary resource markets and enabling innovation (Table 1). Within the theme of "whole system approaches identifying key intervention points", contrasts were particularly stark around the enabling of a circular economy through (decentralised) infrastructure. Overall comparison of themes in Table 1 reveals that there are strong regional differences within the UK. This raises the question of to what extent context-specific approaches are required, and how this could be balanced within strategies and plans for the whole UK to move all nations forward to a more circular economy.

\section{Conclusions and Recommendations}

This article shed light on the undercurrent of perspectives within governmental organisations that drive resource recovery and circular economy. Experts in waste and resource management in British governmental organisations broadly agreed on a vision of a circular economy that focusses on maximizing the value created from materials whilst keeping them in the economy for as long as possible. They also agreed that a move away from end-of-pipe approaches, and instead designing durability and recyclability into the economy, was necessary. A practical circular economy strategy was seen to require:

(1) Integration of economic with social and environmental values, metrics, and models; this applied to all government departments, and especially the Treasury; 
(2) Support for secondary resource markets, for example, under the guidance of the Department for Business, Energy, and Industrial Strategy (BEIS), and the Department for Environment, Food, and Rural Affairs (Defra) and their devolved counterparts;

(3) Policy interventions that enable innovation not just in waste processing technology but also in business models, product design, and data collection and analysis through the work of UK Research and Innovation; many of these will rely on the increased exploitation of digital and data technologies that are analogous to those in construction (e.g., CAD [computer aided design], BIM [building information modelling]) or financial technology (e.g., blockchain);

(4) Adoption of a whole-systems approach to analysis (aided by academics), but a recognition that the government operates in departments, and thus translation of whole-system recommendations into specific actions can be steered through key intervention points, under the leadership of the Cabinet and their devolved counterparts supported by a new Office for Resource Stewardship [26,32].

To deliver such a circular economy, the government needs to collaborate with partners across society to integrate scientific research, policies, and regulations. The government must adopt a long-term and predictable policy framework focussed on resource efficiency and building on the EU circular economy package in line with the decarbonisation agenda. This should be allied to a clear pipeline of forthcoming projects and interventions similar to that adopted by the National Infrastructure Plan in order to reduce uncertainty and investment risk, unlocking new finance and business models. A mix of supporting regulatory approaches needs to be developed, including (a) taxation; (b) reporting; (c) extended producer and consumer responsibility; (d) product bans or standards; (e) mandatory recycling regimes; and (f) a new Waste Prevention Act.

Comparison of the personal expert views to the formal government positions shows that a part of the proposed vision and approach has already perpetuated into strategies and plans. However, differences in policy and regulation across the four nations in the UK are large, and any existing coherence appears to be driven by a desire to comply with EU directives. Clearly, the UK's current intention to drastically change its relationship with the EU, and thus the degree to which the UK as a whole and individual nations continue to implement such directives, e.g., the EU Circular Economy Package, will disrupt this coherence unless concerted policy action is taken soon. Comparing the government views to the RRfW's perspective (see Velenturf and Purnell [8]), attention for the social impacts (such as air quality) and benefits (for example high-quality jobs) is generally lower in government; we note that relations between waste and resource management and "social" aspects, such as well-being, and human rights in the UK, need more research and communication, and this could in part be delivered via academic research. Moreover, further action is needed to maintain the technical qualities of materials (and thus their ability to contribute to industrial productivity i.e., the status as resources, not wastes) rather than losing them through, for example, disproportionate reliance on energy-from-waste and export; this will require a change in the investment profile of the Infrastructure and Projects Authority.

The promising and increasingly coherent strategies of the British government now need to be translated into practice. This will require the inclusion of more diverse values and metrics in government plans and models that measure technical, social, and environmental costs and benefits as well as economic; it is likely to require a step-change in the ways that resource and waste flow data are collected and analysed. It will also require an alignment of public investment with the ambitions for a growing, low-carbon, and zero avoidable waste economy that increases resource productivity and creates jobs in all of the regions of the UK as the government envisions.

Academia should contribute to government processes by keeping a watchful eye on the 'bigger picture' whole-systems research, and also translating this into communications to government departments that explain how their various, specific decisions interact with—and impact—on the growing circular economy. Academics should recommend to government how greater coherency in governance as well as policies and regulations can achieved. Regular contact with governmental 
organisations enables the provision of the timely and concrete recommendations that are needed in the governance process. Research programmes such as those funded via UK Research and Innovation must be designed to enable such collaboration with government and other relevant organisations [8]. RRfW will continue to collaborate with governmental organisations and translate project outcomes into concrete recommendations for specific government bodies. Moreover, the programme will continue to bring together the relevant actors in government, industry, and academia with the aim to actively contribute to the transition to a circular economy.

Author Contributions: A.P.M.V. conceived and designed the study with contributions from P.P. and A.H.; A.P.M.V. collected and analysed the data and wrote the paper with contributions from P.P., M.T., J.F. and A.H.

Acknowledgments: The authors are grateful for the engagement of all (former) government participants in the preparation of this manuscript including Lee Davies, Andrew Dickson, Arjan Geveke, Alan Holmes, Helen Jamieson, Louise McGregor, Kenneth O'Callaghan, Caroline Spencer and Andrew Woodend. The insightful contributions from Andy Rees and Ann Humble are also much appreciated. Resource Recovery from Waste is convened with funding from the Natural Environment Research Council, Economic and Social Research Council and DEFRA via the Complex Value Optimisation for Resource Recovery grant NE/L014149/1.

Conflicts of Interest: The authors declare no conflict of interest. While the founding sponsors did task the RRfW Programme Coordination Team with the formulation of a shared vision with relevant organisations working on resource recovery in the UK, they had no role in the design of the study; in the collection, analyses, or interpretation of data; in the writing of the manuscript, and in the decision to publish the results.

\section{References}

1. Dobbs, R.; Oppenheim, J.; Thompson, F.; Brinkman, M.; Zornes, M. Resource Revolution: Meeting the World's Energy, Materials, Food, and Water Needs; McKinsey Quarterly and Company: Summit, NJ, USA, 2011.

2. Fischer-Kowalski, M.; Swilling, M.; Von Weizsacker, E.U.; Ren, Y.; Moriguchi, Y.; Crane, W.; Krausmann, F.K.; Eisenmenger, N.; Giljum, S.; Hennicke, P.; et al. Decoupling: Natural Resource Use and Environmental Impacts from Economic Growth; A Report of the Working Group on Decoupling to the International Resource Panel; United Nations Environment Programme: Nairobi, Kenya, 2011.

3. Morgan, J. The Great Resource Price Shock; Green Alliance: London, UK, 2014.

4. UNEP. ISWA Global Waste Management Outlook. 2015. Available online: http://apps.unep.org/ publications /index.php?option=com_pub\&task=download\&file=011782_en (accessed on 4 July 2016).

5. Millennium Ecosystem Assessment. Ecosystems and Human Well-Being: Synthesis. 2005. Available online: http:/ / www.millenniumassessment.org/documents/document.356.aspx.pdf (accessed on 4 July 2016).

6. Rockström, J.; Steffen, W.; Noone, K.; Persson, Å.; Chapin, F.S.I.; Lambin, E.; Lenton, T.; Scheffer, M.; Folke, C.; Schellnhuber, H.J.; et al. Planetary boundaries: Exploring the safe operating space for humanity. Ecol. Soc. 2009, 14, 32. [CrossRef]

7. OHCHR and UNEP. Human Rights and the Environment. 2012. Available online: http://www.unep. org/delc/Portals/119/JointReportOHCHRandUNEPonHumanRightsandtheEnvironment.pdf (accessed on 4 July 2016).

8. Velenturf, A.P.M.; Purnell, P. Resource recovery from waste: Restoring the balance between resource scarcity and waste overload. Sustainability 2017, 9, 1603. [CrossRef]

9. Kirchherr, J.; Reike, D.; Hekkert, M. Conceptualizing the circular economy: An analysis of 114 definitions. Res. Conserv. Recyc. 2017, 127, 221-232. [CrossRef]

10. Breman, B.; Pleijte, M.; Ouboter, S.; Buijs, A. Participation in Water Management (Participatie in Waterbeheer); Alterra Wageningen UR: Wageningen, The Netherlands, 2008.

11. Bacon, C.; Mendez, V.E.; Brown, M. Participatory Action Research and Support for Community Development and Conservation: Examples from Shade Coffee Landscapes in Nicaragua and el Salvador; Center for Agroecology and Sustainable Food Systems, University of California: Santa Cruz, CA, USA, 2005.

12. Defoer, T.; De Groote, H.; Hilhorst, T.; Kante, S.; Budelman, A. Participatory action research and quantitative analysis for nutrient management in southern mali: A fruitful marriage? Agric. Ecosyst. Environ. 1998, 71, 215-228. [CrossRef]

13. Bryman, A. Social Research Methods, 4th ed.; Oxford University Press: Oxford, UK, 2012.

14. Mason, J. Qualitative Researching, 2nd ed.; SAGE Publications Ltd.: London, UK, 2002. 
15. Resource Recovery from Waste. Towards a Shared Vision for Waste and Resource Management (1): Effective Government-Academic Collaboration. 2017. Available online: https://www.linkedin.com/pulse/towardsshared-vision-waste-resource-management-1-resource/ (accessed on 8 June 2017).

16. Resource Recovery from Waste. Towards a Shared Vision for Waste and Resource Management (2): Policy and Regulatory Approaches. 2017. Available online: https:/ /www.linkedin.com/pulse/working-towardsshared-vision-waste-resource-2-policy-resource/ (accessed on 8 June 2017).

17. Resource Recovery from Waste. Working towards a Shared Vision for Waste and Resource Management (3): Key Changes and Pivot Points. 2017. Available online: https:/ / www.linkedin.com/pulse/workingtowards-shared-vision-waste-resource-3-key-resource/ (accessed on 8 June 2017).

18. Interpol Environmental Crime Programme. Guide to Carbon Trading Crime; Interpol Environmental Crime Programme: Lyon, France, 2013.

19. Millward-Hopkins, J.; Busch, J.; Purnell, P.; Zwirner, O.; Velis, C.A.; Brown, A.; Hahladakis, J.N.; Iacovidou, E. Fully integrated modelling for sustainability assessment of resource recovery from waste. Sci. Total Environ. 2018, 612, 613-624. [CrossRef] [PubMed]

20. HM Treasury. Valuing Infrastructure Spend: Supplementary Guidance to the Green Book. 2015. Available online: https: / /www.gov.uk/government/publications/green-book-supplementary-guidance-valuinginfrastructure-spend (accessed on 8 June 2017).

21. OECD. Improving Recycling Markets. 2007. Available online: http:/ / www.oecd.org/env/waste/38093900. pdf (accessed on 8 June 2017).

22. WRAP. Materials Pricing Report. 2017. Available online: http://www.wrap.org.uk/sites/files/wrap/9th\% 20Jan\%202017\%20MPR.pdf (accessed on 8 June 2017).

23. Bocken, N.M.P.; Short, S.W.; Rana, P.; Evans, A. A literature and practice review to develop sustainable business model archetypes. J. Clean. Prod. 2014, 65, 42-56. [CrossRef]

24. Accenture. Circular Advantage: Innovative Business Models and Technologies to Create Value in a World without Limits to Growth. 2014. Available online: https://www.accenture.com/t20150523T053139__w_ _/us-en/_acnmedia/Accenture/Conversion-Assets/DotCom/Documents/Global/PDF/Strategy_6/

Accenture-Circular-Advantage-Innovative-Business-Models-Technologies-Value-Growth.pdf (accessed on 8 June 2017).

25. Hahladakis, J.N.; Velis, C.A.; Weber, R.; Iacovidou, E.; Purnell, P. An overview of chemical additives present in plastics: Migration, release, fate and environmental impact during their use, disposal and recycling. J. Hazard. Mater. 2018, 344, 179-199. [CrossRef] [PubMed]

26. Purnell, P. On a voyage of recovery: A review of the UK's resource recovery from waste infrastructure. Sustain. Res. Infrastruct. 2017, 1-20. [CrossRef]

27. Jensen, P.D. The role of geospatial industrial diversity in the facilitation of regional industrial symbiosis. Res. Conserv. Recyc. 2016, 107, 92-103. [CrossRef]

28. BuroHappold. Help or Hindrance? Environmental regulations and competitiveness. 2017. Available online: http:/ / www.aldersgategroup.org.uk/latest\#beyond-red-tape-smart-regulations-are-keyto-delivering-uk-industrial-and-environmental-ambitions (accessed on 14 December 2017).

29. Chartered Institute of Waste Management. Reuse in the UK and Ireland. Available online: http:/ / www. ciwm-journal (accessed on 8 June 2017).

30. Environment Agency. Guidance: Turn your waste into a new non-waste product or material. Available online: https: / / www.gov.uk/guidance/turn-your-waste-into-a-new-non-waste-product-or-material (accessed on 2 May 2018).

31. NAO (National Audit Office). The Impact of Funding Reductions on Local Authorities. 2014. Available online: https:/ / www.nao.org.uk/report/the-impact-funding-reductions-local-authorities / (accessed on 7 January 2015).

32. Velenturf, A.P.M. Analysing the governance system for the promotion of industrial symbiosis in the humber region, UK. People Place Policy 2016, 10, 146-173. [CrossRef]

33. Velenturf, A.P.M. Promoting industrial symbiosis: Empirical observations of low-carbon innovations in the humber region, UK. J. Clean. Prod. 2016, 128, 116-130. [CrossRef]

34. Welsh Assembly Government. Towards Zero Waste, the Overarching Waste Strategy. 2010. Available online: http:/ / gov.wales/docs/desh/publications/100621wastetowardszeroen.pdf (accessed on 14 December 2017). 
35. Welsh Assembly Government. One Wales: One Planet, the sustainable development scheme of the Welsh Assembly Government. 2009. Available online: http://www.assembly.wales/Laid\%20Documents/ GEN-LD7521\%20-\%20One\%20Wales\%20One\%20Planet\%20-\%20The\%20Sustainable\%20Development\% 20Scheme\%20of\%20the\%20Welsh\%20Assembly\%20Government-22052009-130462/gen-ld7521-e-English. pdf (accessed on 14 December 2017).

36. Carl Sargeant (Minister for Natural Resources). Written statement - Achieving a More Circular Economy for Wales. 2016. Available online: http:/ / gov.wales/about/cabinet/cabinetstatements / previousadministration/2016/ circulareconomy/?lang=en (accessed on 14 December 2017).

37. Welsh Government. Cabinet Secretary confirms $£ 6.5 \mathrm{~m}$ ‘Circular Economy' fund. 2017. Available online: http:/ /gov.wales/newsroom/environmentandcountryside/2017/170310-cabinet-secretary-confirms-6mcircular-economy-fund/?lang=en (accessed on 14 December 2017).

38. Welsh Government. Natural Resources Policy. 2017. Available online: http://gov.wales/docs/desh/ publications/170821-natural-resources-policy-en.PDF (accessed on 14 December 2017).

39. Welsh Government. Well-being of Future Generations (Wales) Act 2015. 2016. Available online: http: / / gov.wales/topics / people-and-communities / people/future-generations-act/?skip=1\&lang=en (accessed on 14 December 2017).

40. Welsh Government. Environment (Wales) Act 2016. 2016. Available online: http://gov.wales/topics/ environmentcountryside/consmanagement/natural-resources-management/environment-act/?lang=en (accessed on 14 December 2017).

41. Welsh Government. Prosperity for All: The National Strategy. 2017. Available online: http://gov.wales / docs/strategies/170919-prosperity-for-all-en.pdf (accessed on 14 December 2017).

42. Natural Scotland. Zero Waste Plan. 2010. Available online: http://www.gov.scot/Resource/0045/00458945. pdf (accessed on 14 December 2017).

43. European Commission. Circular Economy: Implementation of the Circular Economy Action Plan. 2018. Available online: http:/ / ec.europa.eu/environment/circular-economy/index_en.htm (accessed on 12 March 2018).

44. Natural Scotland. Making Things Last. 2016. Available online: http://www.crni.ie/wp-content/uploads / 2017/02/natural_scotland_ce_strategy_making_things_last.pdf (accessed on 14 December 2017).

45. Natural Scotland. Zero Waste. Safeguarding Scotland's Resources: Blueprint for a More Resource Efficient and Circular Economy. 2013. Available online: http://www.gov.scot/Resource/0043/00435308.pdf (accessed on 14 December 2017).

46. Scottish Government. A Manufacturing Future for Scotland. 2016. Available online: https: / / scottishmasconference.co.uk/wp-content/uploads/2017/07/A-manufacturing-future-for-Scotland.pdf (accessed on 14 December 2017).

47. Scottish Government. Scotland's Economic Strategy. 2015. Available online: http://www.gov.scot/ Resource/0047/00472389.pdf (accessed on 14 December 2017).

48. Government Office for Science. From Waste to Resource Productivity: Main Report. 2017. Available online: https: / www.gov.uk/government/uploads/system/uploads/attachment_data/file/667476/fromwaste-to-resource-productivity-final-report.pdf (accessed on 14 December 2017).

49. Cave, S. Background Paper on Waste Management in Northern Ireland; Northern Ireland Assembly Research and Information Service: Belfast, UK, 2016.

50. Department of Environment. Delivering Resource Efficiency: Northern Ireland Waste Management Strategy. 2013. Available online: https:/ /www.daera-ni.gov.uk/sites/default/files/publications/doe/waste-policydelivering-resource-efficiency-northern-ireland-waste-management-strategy-2013.pdf (accessed on 14 December 2017).

51. Northern Ireland Executive. Everyone's Involved: Sustainable Development Strategy. 2010. Available online: https:/ / www.nienvironmentlink.org/cmsfiles/policy-hub / files / documentation/Waste/ Sustainable-Development-Strategy.pdf (accessed on 14 December 2017).

52. Department of Environment. The Waste Prevention Programme for Northern Ireland: The Road to Zero Waste. 2014. Available online: https:/ / www.daera-ni.gov.uk/sites/default/files/publications/doe/wasteprevention-programme-NI-road-zero-waste-2014.pdf (accessed on 14 December 2017).

53. DEFRA (Department for Environment, Agriculture and Rural Affairs). Government Review of Waste Policy in England. 2011. Available online: https:/ / www.gov.uk/government/uploads/system/uploads / attachment_data/file/69401/pb13540-waste-policy-review110614.pdf (accessed on 14 December 2017). 
54. DEFRA (Department for Environment, Agriculture and Rural Affairs). Waste Management Plan for England. 2013. Available online: https://www.gov.uk/government/uploads/system/uploads/attachment_data/ file/265810/pb14100-waste-management-plan-20131213.pdf (accessed on 14 December 2017).

55. DEFRA (Department for Environment, Agriculture and Rural Affairs). Waste Management Plan for England-Post Adoption Statement. 2013. Available online: https:/ /www.gov.uk/government/uploads / system/uploads/attachment_data/file/265543/pb14101-waste-manage-post-adopt-20131212.pdf (accessed on 14 December 2017).

56. HM Government. Prevention is Better than Cure: The Role of Waste Prevention in Moving to a More Resource Efficient Economy. 2013. Available online: https://www.gov.uk/government/uploads/system/uploads/ attachment_data/file/265022/pb14091-waste-prevention-20131211.pdf (accessed on 14 December 2017).

57. DEFRA (Department for Environment, Agriculture and Rural Affairs). Quality Action Plan: Proposals to Promote High Quality Recycling of Dry Recyclates. 2013. Available online: https://www.gov. uk/government/uploads/system/uploads/attachment_data/file/221028/pb13875-qap-recycling.pdf (accessed on 14 December 2017).

58. HM Government. Industrial Strategy: Building a Britain Fit for the Future. 2017. Available online: https://www.gov.uk/government/uploads/system/uploads/attachment_data/file/664563/ industrial-strategy-white-paper-web-ready-version.pdf (accessed on 14 December 2017).

59. HM Government. The Clean Growth Strategy: Leading the Way to a Low Carbon Future. 2017. Available online: https://www.gov.uk/government/uploads/system/uploads/attachment_data/file/651916/BEIS_ The_Clean_Growth_online_12.10.17.pdf (accessed on 14 December 2017).

60. HM Government. A Green Future: Our 25 Year Plan to Improve the Environment. 2018. Available online: https: / www.gov.uk/government/publications/25-year-environment-plan (accessed on 16 January 2018).

61. WRAP. Securing the Future-The Role of Resource Efficiency. 2010. Available online: http:/ /www.wrap. org.uk/sites / files / wrap/Securing\%20the\%20future\%20The\%20role\%20of\%20resource\%20efficiency.pdf (accessed on 14 December 2017).

62. IPA. National Infrastructure Delivery Plan 2016-2021. 2016. Available online: https://www.gov.uk/ government/uploads /system/uploads /attachment_data/file/520086/2904569_nidp_deliveryplan.pdf (accessed on 8 June 2017). 